\title{
Respiratory Tract Hemorrhage
}

National Cancer Institute

\section{Source}

National Cancer Institute. Respiratory Tract Hemorrhage. NCI Thesaurus. Code C78596.

Bleeding originating from any part of the respiratory tract. 